\title{
Die Heilkraft der Poesie
}

Das Unispital und die ETH Zürich, die lehren das Fach Medizin-Poesie.

Das Departement für die Klinische Lyrik heisst «Dichtende Weisskittel-Akademie».

Man hat nämlich neuerdings feststellen können, dass Dichtung das Wohlergehn stark unterstützt. Auch sind Analysen und Studien zu nennen, die zeigen, dass Lyrik vor Krankheiten schützt.

Vielleicht tut der Rhythmus mit jeder Betonung uns achtsam erinnern an Atmung und Herz? Vielleicht ist der Reim wie die eigene Wohnung ein trautes Zuhause mit Drang himmelwärts?

Solch Forschung wär wichtig, doch muss ich gestehen, die Einrichtung Zürichs ist nurmehr ein Nichts. Vielleicht mal in Zukunft? Wir werden es sehen, denn heilsam bleibt sicher die Kraft des Gedichts.

Dr. med. Christoph Zwisler, Brunnen

ch.zwisler[at]gmail.com Bildnachweis: Finwal | Dreamstime.com

.

\section{B. Bidnachweis: Finwal|Dreamstime.com}

